\title{
El microrrelato dermatológico o ¿hasta dónde «menos es más»?
}

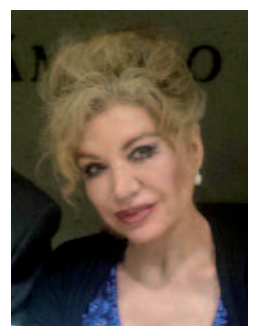

Aurora Guerra Tapia

Profesora titular de Dermatología. Departamento de Medicina.

Facultad de Medicina.

Universidad Complutense

de Madrid.

Jefa de Sección de Dermatología.

Hospital Universitario

12 de Octubre. Madrid.

Profesora de Dermatología.

Universidad Internacional

de La Rioja (UNIR).

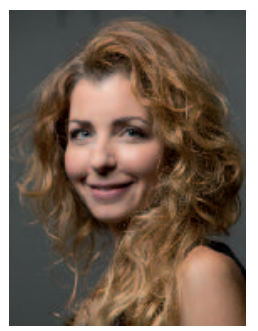

\section{Elena González-Guerra}

Profesora asociada de Dermatología. Departamento de Medicina.

Facultad de Medicina.

Universidad Complutense

de Madrid.

Médico adjunto.

Servicio de Dermatología.

Hospital Clínico San Carlos. Madrid.

Profesora de Dermatología.

Universidad Internacional

de La Rioja (UNIR).
«Lo bueno, si breve, dos veces bueno».

BALTASAR GRACIÁN

(1601-1658).

Dice el Diccionario de la lengua de la Real Academia Española que microrrelato (de micro y relato) es un «relato muy breve». Y no necesita más adornos dicha definición, suficientemente concisa y tan breve como la propia palabra descrita.

Pero, aunque el vocablo como tal deviene en su uso literario de la segunda mitad del siglo Xx, el concepto estaba inventado en los comienzos de la historia, casi al mismo tiempo que la escritura. Es fácil encontrar ejemplos en las composiciones narrativas de los sumerios, en los textos cortos de los papiros egipcios y en algunos libros bíblicos como los Proverbios, el Libro de Job, el Eclesiastés o el Cantar de los cantares, así como en las parábolas de Jesús del Nuevo Testamento. También las culturas griegas (Homero, Herodoto, Esopo), romanas (Petronio, Juvenal) y orientales (Chuang Tzu), han dejado ejemplos intensos y perdurables, repetidos y recreados en distintas lenguas.

Si buscamos en el acervo cultural hispánico, hallaremos el origen remoto del microrrelato español en las faecías o cuentecillos e, incluso, en los romances, que, con una estructura narrativa unitaria y completa pese a estar escritos en verso, corrían de boca en boca desde la Edad Media en adelante.

El término microrrelato es utilizado por primera vez en 1977 por el escritor mexicano José Emilio Pacheco (1939-2014), difundiéndose su uso de forma rápida y afortunada. Crece el concepto impulsado por un ambiente social y cultural en el que se potencia la estética de lo mínimo y la poética de la sustracción 
en todos los ámbitos, incluida la literatura. A este motor propulsor se suman el less is more del arquitecto alemán Ludwig Mies van der Rohe (18861969) y, todavía más cerca, las hibridaciones culturales y el mestizaje social, las modernas tecnologías, las redes sociales, los nuevos modos del avance de la publicidad e, incluso, el "grafitismo».

Dicen los expertos ${ }^{1}$ que un microrrelato no es un poema, ni un cuento, ni una sentencia, ni un refrán, ni un haiku oriental, ni un epigrama latino, ni una greguería... Pero no me parece fácil hallar una clara diferencia entre muchos de estos elementos literarios:

«El poeta miró tanto al cielo que le salió una nube en un ojo».

Greguería de Ramón Gómez de la Serna.

«Cuando despertó, el dinosaurio todavía estaba allí».

Microrrelato de Augusto Monterroso.

Lo que sí parece claro es que el microrrelato se puede considerar el último eslabón de la cadena narrativa: novela, novela corta ${ }^{2}$, cuento, cuento corto y microrrelato. Comparte rasgos con todos ellos, sin límites de palabras ni otras normas que lo coarten, pero tiene una fisonomía diferente. No es solo brevedad lo que se requiere. Se necesita, además, precisión. O dicho de otro modo, no es un resumen, sino la esencia de una historia narrada.

Y acabamos en el comienzo, confirmando la definición de la Real Academia Española como idónea: el microrrelato es un relato muy breve.

Y pensemos ahora en la medicina. También nosotros, los médicos, nos servimos del microrrelato, del «menos es más» en nuestro quehacer diario. ¿O no es así cuando aplicamos la economía expresiva y utilizamos la capacidad sintética para redactar una correcta historia clínica?

Evidentemente, sí. ¿No es acaso eso — brevedad y precisión- la anamnesis de un paciente?: «anamnesis: (gr. anámnēsis [aná 'de nuevo' + $m n \bar{e}$ - 'recordar' + -sis] 'recuerdo'): parte inicial de la historia clínica de un enfermo que consiste en la recogida ordenada [...] de información sobre la enfermedad que motiva la consulta, los antecedentes patológicos personales y familiares, los hábitos potencialmente dañinos y el estilo de vida general del enfer$\mathrm{mo}^{3}{ }$.

Puede que sea una opinión temeraria. Pero aún me atrevo a más. Pensando en la dermatología, en el desarrollo de esta especialidad eminentemente visual, he creído vislumbrar una hipérbole del microrrelato: la foto clínica dermatológica y su pie.

Pongamos un ejemplo: evolución de un queloide (fig. 1).
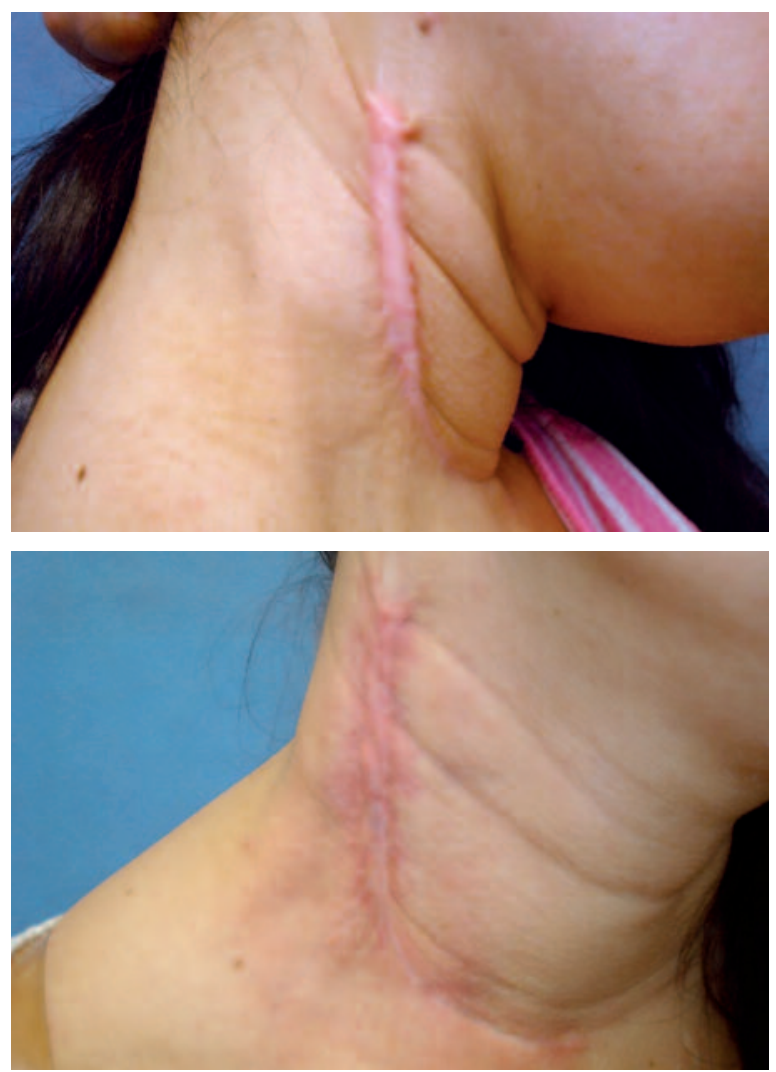

Figura 1. Antes y después de cuatro infiltraciones con triamcinolona. 
Todos los dermatólogos hemos comprendido que la paciente de la imagen, una mujer con una cicatriz queloide tras una intervención quirúrgica, ha sido tratada con cuatro infiltraciones intralesionales de glucocorticoides (triamcinolona), con excelentes resultados terapéuticos.

Esencia de la historia: esta es la excelencia del microrrelato. $\mathrm{O}$, tal vez, nos ciega la pasión por la dermatología.

\section{BIBLIOGRAFÍA}

1. Andrés Suárez I, Rivas A. La era de la brevedad. El microrrelato hispánico. Palencia: Menoscuarto Ediciones; 2008. p. 70.

2. Guerra Tapia A. La novela corta y la medicina: ideas delirantes y alopecia. Más Dermatol. 2016;(24):26-8.

3. Real Academia Nacional de Medicina. Diccionario de términos médicos. Madrid: Editorial Médica Panamericana; 2012. 